\title{
DE AROMAS E PERFUMES, O MERCADO DA INDÚSTRIA DO “CHEIRO”
}

\author{
Marcelo Gomes Speziali \\ Instituto de Química, Universidade Federal do Rio Grande do Sul, Av. Bento Gonçalves, 9500, 91501-161 Porto Alegre - RS, Brasil
}

Recebido em 6/5/11; aceito em 25/10/11; publicado na web em 20/1/12

\begin{abstract}
FROM AROMAS AND PERFUMES, THE MARKET OF THE "SMELL" INDUSTRY. Several flavors and fragrances (F\&F) companies hold the economic leadership in the market, although not always have also the leadership in patent applications. The ranking of technological production in the fragrance area still remains with industries while scientific knowledge is equally shared between industries and academia. Contextualizing Brazil in this scene, despite all scientific expertise gained over the years, brazilian technological park is still at the beginning of the production of technologies applied directly to the F\&F industries. The dependence on foreign technologies is remarkable as indicated by the great trade deficit in this sector.
\end{abstract}

Keywords: market; fragrances; essential oils.

\section{INTRODUÇÃO}

Segundo a resolução No. 22 de 1976 da CNNPA (Comissão Nacional de Normas e Padrões para Alimentos), pertencente ao Ministério da Saúde, aromas são "substâncias ou mistura de substâncias, possuidoras de propriedades sápidas e odoríferas ou somente sápidas, capazes de conferir odor e/ou sabor aos alimentos e bebidas", enquanto que as fragrâncias, por sua vez, são "substâncias dotadas somente de propriedades odoríferas".

Ao pensar em fragrâncias imaginamos logo o cheiro dos perfumes clássicos, como Channel n ${ }^{\circ} 5$, ou mesmo evocamos no nosso íntimo, no inconsciente, aquela lembrança perdida, um momento, uma pessoa, um lugar. Desde tempos imemoriáveis da pré-história, ervas aromáticas, madeiras com cheiro, especiarias, unguentos e similares já eram empregados na culinária para dar cheiro e sabor aos alimentos. No decorrer da nossa história, muitos eventos foram marcados pelo inusitado comportamento de algumas figuras importantes. Nero já dizia que nenhuma orgia estaria completa se não houvesse perfumes. A difusão dos materiais aromáticos teve grande repercussão na Europa devido às incursões de Marco Pólo às Índias e à China e à comercialização de ervas e especiarias. ${ }^{1} \mathrm{~A}$ contribuição à comercialização de materiais aromáticos se deve, também, em grande parte aos navegadores ibéricos. ${ }^{2}$

A arte da construção de um bom perfume vai muito além da ciência com suas intricadas e complexas sínteses de novas fragrâncias. O design de um perfume é devido à arte de um perfumista - artista do mundo das grandes grifes, da moda governada pelo universo da alta costura, trabalhando direta ou indiretamente para as Flavor Houses, servindo muitas vezes de consultores. Para o desenvolvimento de um perfume, normalmente, a primeira etapa é o desenvolvimento da marca e a finalidade, sendo por último determinada a composição química do mesmo. O que regula o lançamento, ou não, de um novo perfume, normalmente, são as tendências do mercado da moda. $\mathrm{O}$ trabalho de um perfumista fica condicionado à captação subjetiva da ideia da marca, construindo quimicamente uma mistura (bouquet) de produtos fornecidos pelas Flavor Houses. Um perfumista trabalhando para a Quest pode ser consultado para o lançamento de um novo perfume de uma grife, tal como Hugo Boss. A inspiração, aliada a uma matéria-prima de qualidade, vai acabar resultando naquele cheiro inesquecível presente naquelas pessoas que marcarão as nossas vidas

e-mail: marcelospz@yahoo.com.br e que vão eternizar alguns momentos. Um químico vê nas cores da natureza motivos para fazer tintas, mas a arte que vai para um belo quadro depende da inspiração de um pintor. A arte que vai para um perfume depende de um perfumista. Maiores detalhes sobre a cronologia do desenvolvimento da química de perfumes, bem como os fatos históricos relevantes e, no mínimo, curiosos, podem ser encontrados em diversos livros de química de fragrâncias. ${ }^{3}$

No campo da Química, vários esforços têm sido feitos no sentido de aumentar a produção de substâncias de grande interesse comercial. Dentre estas substâncias, as fragrâncias representaram cerca $0,6 \%$ de um montante de aproximadamente 58,7 bilhões de dólares na economia brasileira em 2004, ou seja, pouco mais de 350 milhões de dólares. ${ }^{4}$ A título de comparação, o faturamento no mesmo ano pelas grandes indústrias de fragrâncias soma cerca de 17,65 bilhões de dólares. ${ }^{5}$

\section{ANÁLISE TECNOLÓGICA E ECONÔMICA DO SETOR DE FRAGRÂNCIAS}

O setor de aromas e fragrâncias em suas diversas aplicações, tais como, perfumes finos, fragrâncias de base usadas em domissanitários, cosméticos, brindes de borracha, etc., representa não somente um mercado global multibilionário, mas também uma fonte de desenvolvimento científico e de inovação constante. As grandes empresas de fragrâncias, conhecidas como Flavor Houses, se concentram principalmente na Europa, mas estendem suas ramificações por todo o resto do planeta.

O Brasil está ainda em um estágio embrionário nas tecnologias de produtos beneficiados, como as fragrâncias e perfumes, porém, é líder mundial na produção de matérias-primas. Os óleos essenciais são uma das matérias-primas mais importantes na produção de fragrâncias e o Brasil responde, atualmente, por cerca de $50 \%$ da produção mundial de óleo essencial de laranja, que é uma das matérias-primas fundamentais para os aromas e as fragrâncias. ${ }^{6} \mathrm{~A}$ balança comercial brasileira é superavitária em volume, porém é deficitária economicamente, ou seja, o Brasil exporta grandes volumes de óleos essenciais, produto de menor valor agregado, e importa óleos essenciais beneficiados de alto valor agregado. A Figura 1 mostra a variação temporal dos volumes de importação e exportação bem como o valor FOB (Free on Board) de comercialização dos óleos essenciais e matérias-primas necessárias para a confecção de fragrâncias e perfumes. A análise foi feita para os produtos relativos ao código 33 da Nomenclatura Comum 
do Mercosul que compreende: óleos essenciais e resinoides; produtos de perfumaria ou de toucador preparados e preparações cosméticas. ${ }^{7}$

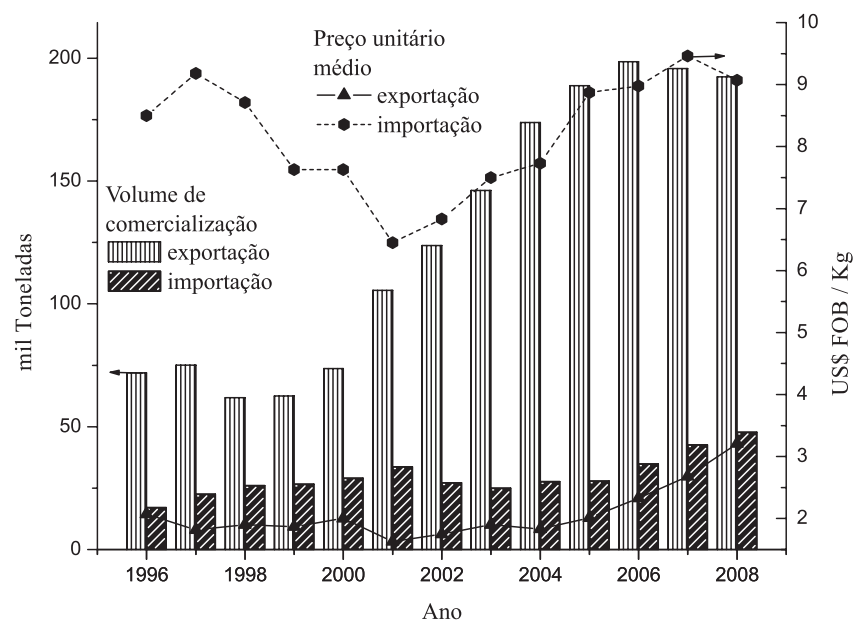

Figura 1. Quantidades em mil toneladas e preço unitário médio para as exportações e importações de óleos essenciais e produtos para a indústria de fragrâncias e higiene pessoal. Fonte: dados obtidos no portal Aliceweb da Secretaria do Comércio Exterior do Ministério do Desenvolvimento, Indústria e Comércio Exterior

É nítida a discrepância entre todos os valores praticados pelo mercado brasileiro no que diz respeito à comercialização de matérias-primas e dos produtos manufaturados com finalidade fragrante. A Tabela 1 retrata a situação brasileira em um contexto mais amplo, no qual os produtos componentes dos aromas e fragrâncias são apenas uma pequena parte no quadro do desequilíbrio da balança comercial brasileira. Todos os produtos da química fina e de performance, essenciais à qualidade de vida das pessoas, são comercializados com valores altíssimos. O pouco produzido no Brasil é vendido a preços baixos e o restante necessário é comprado a valores muito mais altos.

A importância da área das fragrâncias na indústria e na academia se reflete nas intensas pesquisas realizadas e, normalmente, publicadas em artigos, revisões, livros e patentes. Uma análise minuciosa das publicações pode nos dar valiosas informações sobre o setor e os atores envolvidos na cadeia produtiva. Embora o espaço amostral pareça significativo para a análise, não se pode esquecer que todas as áreas estratégicas envolvem muito segredo industrial (Trade Secrets) e com isso, muito conteúdo não divulgado.

A evolução temporal das publicações envolvendo fragrâncias, perfumes e flavorizantes começa a se expressar de modo significativo depois da década de 50, com um crescimento exponencial após esta data (Figura 2). E foi justamente nesta mesma época que o mercado das fragrâncias passou por uma revolução, logo após a declaração da atriz Marilyn Monroe ao dizer que para dormir, entre ela e os lençóis só havia Channel № 5 . Coincidência ou não?

No último século, cerca de 180.000 documentos envolvendo pesquisa científica e tecnológica na área das fragrâncias foram publicados. O número de artigos publicados é muito próximo ao número de patentes depositadas no mesmo período.

Quando analisamos os tipos de publicações geradas ao longo do tempo, fica evidente a participação maciça das instituições de pesquisas, como as universidades, apenas na produção científica de artigos, revisões, seminários, etc. (Figura 3).

A mesma análise restrita aos depósitos de patentes e patentes concedidas demonstra a participação majoritária das grandes empresas neste tipo de publicação tecnológica. Este resultado pode ser

Tabela 1. Situação atual do mercado brasileiro referente à comercialização de produtos de química fina ${ }^{8}$

\begin{tabular}{|c|c|c|c|c|c|c|c|c|}
\hline \multirow{2}{*}{ SETOR } & \multicolumn{4}{|c|}{ Importações (US\$ mil) } & \multicolumn{4}{|c|}{ Exportações (US\$ mil) } \\
\hline & 2005 & 2006 & 2007 & 2008 & 2005 & 2006 & 2007 & 2008 \\
\hline Aditivos & ND & ND & ND & ND & ND & ND & ND & ND \\
\hline Aromas \& Fragrâncias & ND & ND & ND & ND & ND & ND & ND & ND \\
\hline Catalisadores & 105.755 & 110.216 & 136.305 & 163.000 & 34.124 & 56.445 & 44.920 & 60.000 \\
\hline Corantes \& Pigmentos & 157.367 & 186.537 & 235.428 & 279.006 & 60.780 & 78.760 & 76.069 & 83.000 \\
\hline Defensivos Agrícolas & 654.790 & 568.534 & 835.717 & 1.267 .648 & 233.968 & 242.234 & 343.428 & 432.171 \\
\hline Defensivos Animais & ND & ND & ND & ND & ND & ND & ND & ND \\
\hline Farmoquímicos & 1.135 .300 & 1.156 .000 & 1.648 .600 & 2.021 .600 & 273.300 & 286.000 & 351.600 & 341.200 \\
\hline Farmacêutico & 2.036 .964 & 1.802 .315 & 2.330 .519 & 2.732 .000 & 473.290 & 441.982 & 518.404 & 779.000 \\
\hline Total & 4.090 .176 & 3.823 .602 & 5.186 .569 & 6.463 .254 & 1.075 .462 & 1.105 .421 & 1.334.421 & 1.695.371 \\
\hline SETOR & \multicolumn{4}{|c|}{ Saldo Comercial (US\$ mil) } & \multicolumn{4}{|c|}{ Faturamento total (US\$ mil) } \\
\hline Aditivos & ND & ND & ND & ND & ND & ND & ND & ND \\
\hline Aromas \& Fragrâncias & ND & ND & ND & ND & ND & ND & ND & ND \\
\hline Catalisadores & -71.631 & -53.771 & -91.385 & -103.000 & 137.000 & 142.000 & 190.000 & 200.000 \\
\hline Corantes \& Pigmentos & -96.587 & -107.777 & -159.359 & -196.000 & 213.300 & 163.500 & 112.300 & ND \\
\hline Defensivos Agrícolas & -420.822 & -326.300 & -492.289 & -835.477 & 4.243 .748 & 3.850 .000 & 4.500 .000 & 7.100 .000 \\
\hline Defensivos Animais & ND & ND & ND & ND & 917.453 & 1.057 .886 & 1.265 .010 & 1.465 .466 \\
\hline Farmoquímicos & -862.000 & -870.000 & -1.297 .000 & -1.680 .400 & ND & ND & ND & ND \\
\hline Farmacêutico & -1.563 .674 & -1.360 .333 & -1.812 .115 & -1.953 .000 & 9.905 .674 & 11.865 .365 & 14.573 .276 & 17.130 .809 \\
\hline Total & -3.014 .714 & -2.718 .181 & -3.852 .148 & -4.767 .877 & 15.417 .175 & 17.078.751 & 20.640 .586 & 25.896.275 \\
\hline
\end{tabular}

NOTAS: Valores levantados diretamente ou estimados pela ABIFINA. Demais dados são originários de entidades de classe específicas: SINDAN, ABIFRA, SINDAG, ABIFARMA, ABIQUIM e ABIQUIF. 


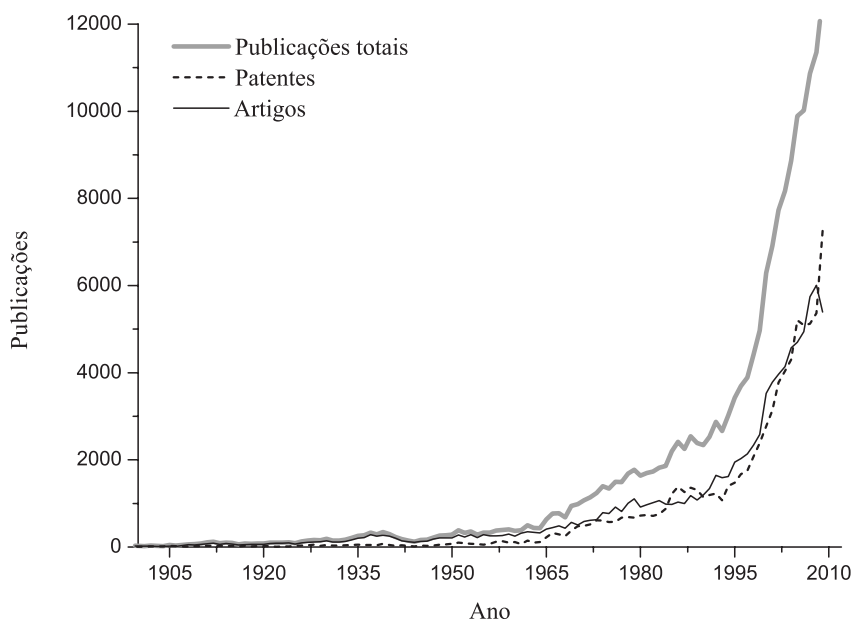

Figura 2. Série histórica do número de publicações envolvendo fragrâncias, perfumes e flavorizantes. Fonte: dados obtidos no SCIFINDER - Web of Science

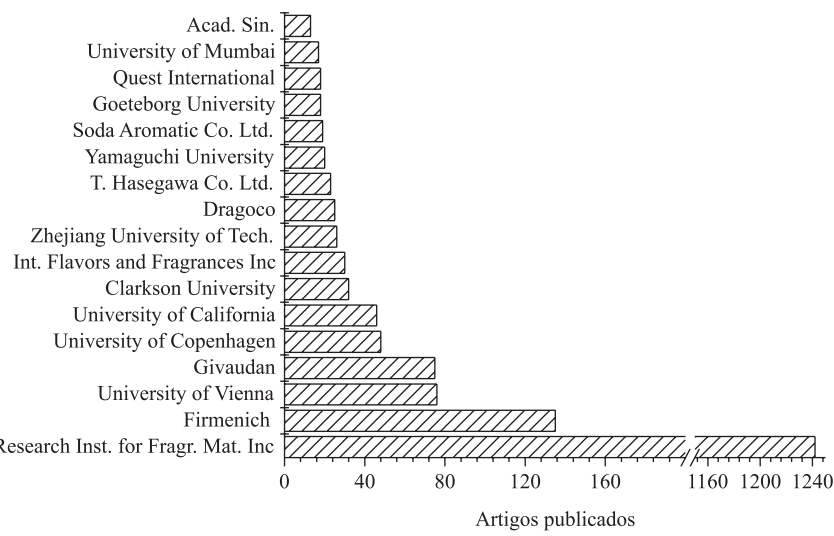

Figura 3. Participação das universidades e empresas nas publicações científicas e tecnológicas da área de fragrâncias, flavorizantes e perfumes nos últimos 30 anos. Fonte: dados obtidos no SCIFINDER - Web of Science

facilmente associado a uma posição estratégica por parte das grandes empresas de fragrâncias. Grande parte dos depositários de patentes nesta área é formada por grupos de inventores independentes e solicitações americanas com depositantes indeterminados, seguido de empresas de alto renome internacional na área de perfumaria - Flavor Houses (Figura 4).

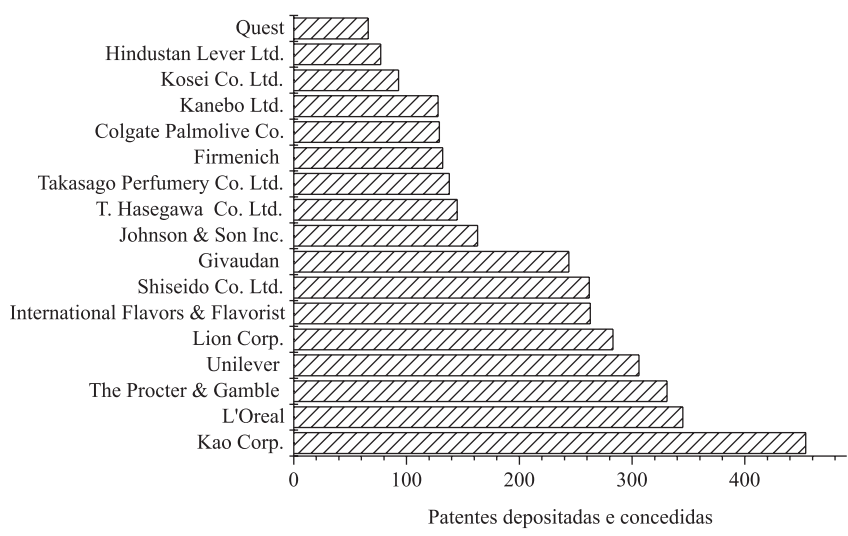

Figura 4. Participação das empresas nos depósitos de patentes na área de fragrâncias, flavorizantes e perfumes nos últimos 30 anos. Fonte: dados obtidos no SCIFINDER - Web of Science
Para melhor compreensão dos nomes das instituições citadas nos gráficos das Figuras 3 e 4, a seguir são citados os nomes completos com os seus respectivos locais de origem: Academy of Science: República Popular da China; Clarkson University: USA; Colgate Palmolive: USA; Dragoco: Alemanha; Firmenich: Suíça; Givaudan: Suíça; Goeteborg University: Suécia; Hindustan Lever Ltd.: Unilever Índia; International Flavor and Fragrances Inc.: USA; Johnson \& Son Inc.: USA; Kanebo Ltd.: Japão; Kao Corporation: Japão; Kosei Co. Ltd.: Japão; L'Oreal: França; Lion Corporation: Japão; Quest International: Holanda; Research Institute for Flavor and Fragrances Materials Inc.: USA; Shiseido Co. Ltd.: Japão; Soda Aromatic Co. Ltd.: Japão; T. Hasegawa: Japão; Takasago Perfumery Co. Ltd.: Japão; The Procter \& Gamble: USA; Unilever: Britânica-Holandesa; University of California: USA; University of Copenhagen: Dinamarca; University of Mumbai: Índia; University of Vienna: Áustria; Yamaguchi University: Japão e Zheijiang University of Technology: República Popular da China.

Percorrendo a complexa cadeia produtiva das fragrâncias e flavorizantes chega-se, enfim, às grandes empresas detentoras da maior expertise e do maior capital econômico nos últimos 5 anos. O mercado controlado por esses atores movimentou cerca de 20 bilhões de dólares somente no ano de 2009, sendo que as 10 maiores empresas do ramo no mundo foram responsáveis por quase $73 \%$ dessa fatia. ${ }^{5}$ Dentre esse valor, as 10 maiores empresas dividem o mercado segundo a Figura 5. Sabendo que Givaudan e Firmenich são as empresas detentoras da maior fatia do mercado, pode-se concluir que a maior parte do capital econômico, concentrado na Europa, reflete a tradição e qualidade secular de manipulação e fabricação de perfumes pelos países do velho continente. Embora sejam as líderes no mercado das fragrâncias e flavorizantes, Givaudan e Firmenich não são as empresas que mais detêm depósitos de patentes. Não esquecendo, novamente, das outras formas possíveis de proteção a uma tecnologia, como o segredo industrial e a marca. As estratégias de proteção de uma empresa são bastante peculiares da própria cultura da empresa e as decisões de proteger ou não uma tecnologia podem variar drasticamente entre as empresas de um mesmo segmento de mercado.

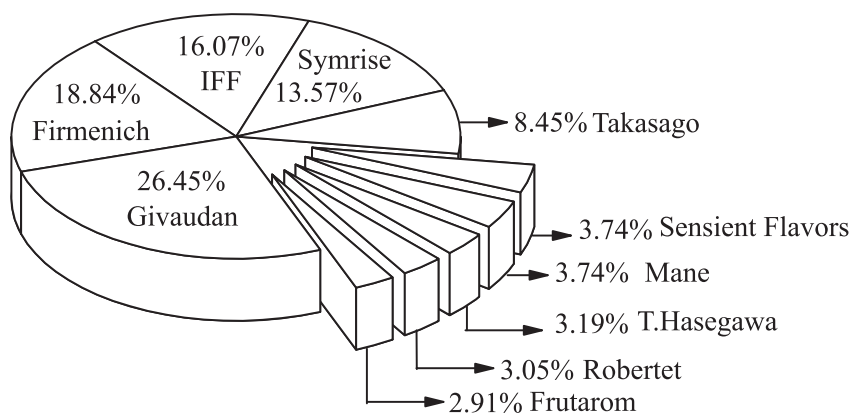

Figura 5. Participação no mercado mundial de flavorizantes e fragrâncias pelas 10 maiores empresas do ramo nos últimos 4 anos

\section{OBSERVAÇÕES FINAIS}

Como mencionado no início, não pretendíamos tratar o assunto de perfumes de forma exaustiva, bem como trabalhar com os detalhes relacionados às teorias modernas da percepção do cheiro. Para aqueles que desejarem se aprimorar no assunto, sugere-se a leitura da obra de Turin ${ }^{9}$ e dos ganhadores do Prêmio Nobel, Axel e Buck. ${ }^{10}$ Várias das substâncias utilizadas em fragrâncias ainda são derivadas de produtos naturais e possuem valores exorbitantes. Sendo extraídas dos óleos essenciais, frequentemente carregam consigo traços de impurezas que são responsáveis por aromas únicos nas substâncias naturais. Apesar do alto valor econômico associado às fragrâncias 
naturais, a pesquisa por fragrâncias sintéticas é crescente devido à possível extinção das fontes de matéria-prima de qualidade. $\mathrm{O}$ desenvolvimento dos processos de síntese das substâncias de interesse, como fragrâncias, evoluiu muito ao longo da história. Contudo, muito investimento público e privado na ciência das fragrâncias deve ser feito até que tenhamos uma melhor compreensão da percepção do cheiro e possamos, com isso, desenhar moléculas com maior poder de sensibilização do olfato, mesmo sendo utilizadas em pequenas quantidades. Apesar de tanta ciência e tecnologia desenvolvidas, justamente, para a obtenção e compreensão do cheiro, o mistério e as emoções subjetivas continuam sendo papel fundamental na criação de novos e duradouros perfumes de qualidade.

\section{AGRADECIMENTOS}

Ao CNPq pela bolsa concedida, a D. Thiele e A. R. Passos pela cuidadosa leitura do manuscrito.

\section{REFERÊNCIAS}

1. Polo, M.; Machado, A. M.; As viagens de Marco Polo, Scipione, 1998

2. Hümmerich, F.; Roteiro da viagem de Vasco da Gama, C. H. Beck, 1898.

3. Poucher, W. A.; Poucher's Perfumes, Cosmetics and Soaps, $9^{\text {th }}$ ed., Chapman \& Hall: New York, 1993, vol. 2; Kirk, R. E.; Othmer, D. F.; Encyclopedia of chemical technology - Noise Pollution to Perfumes, $3^{\text {rd }}$ ed., Wiley-Interscience: New York, 1981; Kirk, R. E.; Othmer, D. F.;
Encyclopedia of chemical technology - Enamels, Porcelain or Vitreous to Ferrites, $3^{\text {rd }}$ ed., Wiley-Interscience: New York, 1981; Sell, C. Em Handbook of essential oils: science, technology, and applications; Baser, K. H. C.; Buchbauer, G., eds.; CRC Press: London, 2010, cap. 5; Sell, C.; The Chemistry of Fragrances: From Perfumer to Consumer, $2^{\text {nd }} \mathrm{ed}$., Royal Society of Chemistry: Cambridge, 2006; Classen, C.; Howes, D.; Synnott, A.; Aroma: The Cultural History of Smell, Taylor and Francis: London, 2002.

4. de Oliveira, N. B.; Quim. Nova 2005, 28 (Supl.), S79.

5. www.leffingwell.com, acessada em Janeiro 2012.

6. http://www.citrusbr.com/exportadores-citricos/setor/exportacoesbrasileiras-do-complexo-citricola-193132-1.asp, acessada em Janeiro 2012 .

7. http://aliceweb.desenvolvimento.gov.br/, acessada em Janeiro 2012.

8. http://www.abifina.org.br/estatisticas.asp, acessada em Janeiro 2012.

9. Turin, L.; Chem. Senses 2008, 33, 683; Turin, L.; Tls-the Times Literary Supplement 2006, 15; Turin, L.; Chemical \& Engineering News 2003, 81, 2; Turin, L.; J. Theoretical Biol. 2002, 216, 367; Turin, L.; Chem. Ind. 1997, 866; Turin, L.; Chem. Ind. 1997, 924; Turin, L.; Chem. Senses 1996, 21, 773; Turin, L.; O’Hare, M.; New Scientist 2006, 192, 74; Turin, L.; Yoshii, F. Em Handbook of Olfaction and Gustation Revised and Expanded; Doty, R. L., ed.; $2^{\text {nd }}$ ed.; Marcel Dekker Ltd: New York, 2003, cap. 13.

10. Buck, L. B.; Axel, R.; Cell 1991, 65, 175; http://nobelprize.org/nobel_ prizes/medicine /laureates/2004, acessada em Janeiro 2012. 